\title{
Facing the Challenges of Sexual Abuse in Persons with Disabilities
}

Sandra S. Cole, AASECT, CSE, CSC

\section{Definition}

Child abuse has been defined in the literature to include any act of commission or omission that endangers or impairs a child's physical or emotional health and development. It may be evidenced by an injury or series of injuries appearing to be non-accidental in nature and which cannot reasonably be explained. The most frequently recognized forms of child abuse are physical abuse (including neglect or lack of adequate supervision) emotional abuse or deprivation and sexual abuse. ${ }^{1}$

All children, unfortunately, are candidates to experience sexual abuse. This includes children who were born with or have acquired a disability. They may be living in foster homes or institutions or with their families.

Sexual abuse can consist of visual, physical or verbal aggression which can be perceived as unwanted sexual activity. This is particularly true about the victim who is less than the age of consent. Sexual assault or abuse includes any form of unwanted sexual touching, nonconsensual sexual intercourse, other ongoing sexual exploitation, or perhaps isolated incidences of physical harassment which is experienced as sexual intent.

The Illusion Theatre in Minneapolis, Minnesota defines sexual abuse as occurring when a person is "manipulated, tricked or forced into touch or sexual contact." A helpful defi-

Reprint requests may be directed to Sandra S. Cole AASECT, CSE, CSC Clinical Professor/Health Educator University of Michigan Medical School, Ann Arbor, Michigan, 48109 . 
nition of sexual abuse to use with children is: forced or tricked touch or sex. This touch can begin anywhere on your body and may mean the person touches your breasts, buttocks, the vagina or penis. Sexual abuse can also involve oral, anal or vaginal penetration. Rape is sexual abuse with penetration. For children, a way to discuss penetration is to say that one part of a person's body (finger, tongue or penis) goes into a part of another person's body (vagina, anus, mouth). Penetration may occur with an object or a body part.

There is also sexual abuse without touch as when someone forces or tricks another person to look at their genitals or forces or tricks an individual into exposing his or her own genitals. Another type of sexual abuse without touch is an obscene phone call, as when a person calls and talks about sex (ways he/she wants to touch a person's body or be touched him/herself)."

Sexual abuse of children involves someone too young to give informed consent but who has been involved in a sexual act. The exploitation of an individual who lacks adequate information to recognize such a situation or who is unable to understand or communicate is also labeled sexual abuse (i.e. the mentally or physically disabled, children).

Sexual abuse or assault is a violation of the whole person and is not restricted to "just a sexual act." It results in indignation and an overwhelming sense of violation and invasion which can affect the victim in a physical, psychological and social way. Frequently the aftermath of the assault or abuse is more severe than the actual event. This is particularly true of disabled individuals who cannot (or do not) access support systems and services that may be available.

It is a crime committed by adults who have forgotten or not adequately learned that it is their responsibility to protect children or to respect the privacy and integrity of another person. These adults instead force or coerce their victims into sexual encounters, the specifics and ramifications of which are beyond their comprehension. For many reasons, these victims cannot resist what they perceive as the authority of the offender.

The effects of these crimes may be short-term, but in many cases there is virtually irreparable psychological harm done to the victim. Sexual exploitation, molestation and incest are 
devastating types of abuse. Some explanation will clarify here that victims include children but also frequently include women, adolescents, the disabled (physically or intellectually) and the female sexual partners of aggressive dominant men, especially if fear of abandonment because of children is involved. The societal taboos surrounding this type of abuse have kept it from widespread exposure. Until recently, it has received very little publicity, helping to keep it a hidden form of abuse. The media is now daily recording such events and demanding our attention.

The nature of sexual abuse also makes it difficult to observe and therefore more threatening to report. The guidelines given for its detection are by no means comprehensive. Several publications are now available in the literature to assist and guide the public and professionals in recognizing signs and symptoms of sexual abuse. These symptoms may exist singly or in various combinations of behavior and attitude as well as physical manifestations.

Illusion Theatre ${ }^{2}$ reminds us that it is important to remember that this form of abuse can make a child or individual both a victim and a prisoner. Those who seek help are often accused of lying. This results in embarrassment, fear, shame and confusion. Society particularly does not want to accept the fact that disabled persons have become victims of abuse, assault or rape. The assumption that this is unthinkable creates even more difficulty for persons with disabilities to receive specific services which could help to protect them. Many people perceive the disabled as asexual or not eligible to receive the attention of others in a sexual way. These resistant attitudes are pervasive and also exist in agencies, facilities, courts, homes and police stations. Families don't want to hear/believe these things. This disbelief can result in unnecessary questioning and pressure on the victim, adding yet another burden of victimization. ${ }^{3}$

\section{A Perspective}

As children we are taught to obey adults and persons in authority. In addition, victims of sexual abuse are often pressured into secrecy about sexual activity by the abuser, leaving the victim feeling helpless and guilty about the behavior. Vic- 
tims often perceive that they have no place to turn for help and no acceptable way out. Frequently they have been coerced, manipulated, bribed or threatened. Frequently they are filled with feelings of self-blame, fear and, for the physically disabled, increased concerns about being repulsive to others.

Children, adults with disabilities, intellectually impaired individuals and those in institutions can experience feelings of social powerlessness which make them particularly vulnerable to exploitation and they may not able to exert their will against the will of the offender. In some cases the victim does not fully understand what is happening because of intellectual limitations, a lack of experience, or a lack of knowledge. It is also recognized that powerlessness of children, disabled or otherwise limited individuals is socially legitimized and even supported. Isolation from society is a major contributor to this feeling of powerlessness. Inability to be viewed as adult or credible because of societal myths about their abilities and rights further contributes to potential exploitation.

It is dehumanizing to be objectified because of a disability. It is further dehumanizing to be omitted or disbelieved as ever being a candidate for molestation, exploitation or assault. In some cases sexual abuse is not viewed as a serious crime because it occurred to someone who is considered "different" or lacking in power and dignity. The perceived damage won't affect society as a whole or in general; therefore, it won't get the full attention of society.

In the last few years, there has been an increase in the media reporting of sexual abuse. ${ }^{4}$ Statistics have been presented which speculate that a child is molested every two minutes in the United States. The majority are between the ages of eight and thirteen. Some estimated that for every victim revealed, nine are hidden from authorities. Because of recent events, we now are forced to recognize that thousands of youngsters fall prey to deviant day care workers, teachers, coaches and others entrusted with their care. Recent television programs have devoted extensive attention to this topic. The parallel here is that the disabled or institutionalized who are dependent on others fall prey to their care providers in the same way as do children to their assailants. At present, society does not really recognize these parallels. 


\section{Characteristics}

Finkelhor ${ }^{5}$ in his recent studies indicates that a quarter of all abuse occurs before the age of seven. Others suggest that over a third of all those who suffer sexual abuse are victimized before the age of nine. These statistics vary depending on different reference sources, and it is difficult to know the exact numbers which occur because each study has its own limitations. But it is important to recognize the fact that probably most assaults and molestation events are not reported or reflected in the statistics at all. A general estimation is that $20 \%$ of cases are reported, the rest are silenced. One of the most uncomfortable facts is that perhaps as much as $50 \%$ of sexual abuse occurs within the family ${ }^{4}$ (again statistics vary depending on the study).

Sexual abuse is a crime almost always suffered in silence, shrouded in such fear that the offenders are able to continue for years or perhaps a lifetime without being apprehended. It is recognized that the average molester may have abused as many as an appalling total of 70 victims. Many speculations estimate that a typical offender within the family may have committed as many as 80 acts of incest with female children. It is recognized that child molesters also reveal far more sexual assaults than the number for which they were originally charged. Sex offenders can be sentenced ranging from dismissal and forgiveness to forty years in prison.

Facts about family sexual abuse can be disturbing and confusing. Families differ in values surrounding touch and behavior. A distinction must be made between normal family practices of affection, touching and interaction and that which is defined as incest. Touching, communication patterns, behavior and play patterns may change from culture to culture and family to family. Families will react in different ways to hugging, cuddling and snuggling of children, to levels of nudity permitted in the family and permissible topics of conversation. Families of disabled children frequently are on either extreme-avoidance of touch (affectional deprivation) or excessive touch (overcompensating, especially with touch). This can confuse both child and adult and appropriate boundaries are crossed or blurred.

The Illusion Theatre has created a "touch continuum"2- 
the difference between good touch and bad touch and what you do when the touch is confusing. "Most touch is good: That means it feels good, warm, fun or playful. Good touches may include a kiss, hug or handshake. Some types of touch are bad: That means the touch hurts our feelings or our bodies. Bad touches may include a slap, kick or punch. Bad touch also includes sexual abuse - where the touch is tricked or forced sexual contact. Some types of touch are confusing: that means we are mixed up about whether the touch is good or bad, but we do know that something doesn't make sense or feel right. The good or fun touches, including tickling, wrestling, or 'touch games' can become confusing if it doesn't feel like a game anymore or we begin to feel uncomfortable, mixed up or hurt by the touch. Sometimes people are not used to touch, or don't like to be touched. We need to respect people's right not to be touched if they don't want to be. We also need to understand that severe deprivation of touch has some of the same effects on children as abusive touch and leaves them very vulnerable to being manipulated by what seems to be affectionate contact." We need to consider the importance of teaching these principles, particularly to persons with disabilities and their families.

\section{Special Considerations}

Exploitive situations become more complicated when individuals have a developmental or physical disability. In some cases involving sexual abuse, when the offender is identified as a family member or perhaps care provider, the victim may be unaware of being victimized and may lack the information to recognize exploitation or may be confused about what the activity really means or what the intent of the offender is. ${ }^{6}$ In fact, frequently the victim is told that this activity is "special," and in return for compliance and secrecy will be given rewards. Of paramount importance in these situations is recognizing that frequently the individual who is dependent on relatives and care providers for personal care (i.e. hygiene, dressing, grooming) can become very confused and unable to distinguish appropriate affectionate behavior and touch from exploitative touch which is expressly designed for the sexual gratification of the offender- not the victim. 
This inability to differentiate basic assistance with personal care activities of daily living (ADL) from sexual exploitation renders them ultimately vulnerable. In a recent NIMH study by the Institute for the Study of Sexual Assault (ISSA) which was designed to identify patterns of sexual abuse of patients in psychiatric settings, it was discovered that orderly psychiatric aides, technicians, and nurses (predominantly male staff) were the most frequent offenders. Their victims were patients, mostly female, who were most dependent and needing constant physical contact. "Testing" of the patient which involved gradual escalation of physical contact wherein the victim was assessed for cooperation resulted in staff perpetrator assaults which included the full range of sexual acts: intercourse, oral copulation, masturbation and/or sexual battery. The study also reports that, although staff assailants often did not directly force patients, they simply took advantage of them because many were completely helpless, in restraints, medicated or in some cases physically limited.

The physical affects of sexual abuse may range from almost nonexistent to venereal disease or pregnancy. Violent attacks often result in bruises and lacerations. Although relatively few instances of sexual molestation are rape or committed with intended violence, it is very easy for the larger, more powerful person to cause serious injury to the child or to the physically limited individual whether or not they resist or try to defend themselves.

\section{Emotional Impact of Abuse}

It is well recognized that the two factors of shame and guilt (either one or the other or both in tandem) are the prime psychological injuries. Both of these devastating repercussions are the result of the internalization of the offense. Victimized individuals frequently view themselves as the cause and as responsible and perhaps ultimately "bad."

Shame is the emotion most experienced out of feelings of defeat and weakness in such situations. There is a sensed loss of self-control with accompanying loss of self-esteem. Victims may be pressured, forced or tricked and still feel themselves to be accessories to the sexual activity even though they do not truly consent and/or perhaps do not fully understand. The 
adult can completely dominate and manipulate the victim. Following these experiences is a loss of self-esteem. The main dilemma of shame is that it becomes a part of the individual's personality. When this happens, shame manifests itself in the feeling that the individual has no worth to self or society. Thus, another "disability" is added to the existing physical or intellectual disability of victims.

One of the more common fears of victims is that of being abandoned. Children and dependent or limited individuals particularly can feel at risk if they are unsafe in their environment. When adults do not believe them, or if disclosure threatens their safety, they are further victimized. In some cases this can lead to the belief that they are deserving of this punishment and they begin to experience not only a loss of self-esteem but a general discounting from family members or society.

The victim can also feel the devastating psychological effects of guilt. The individual may have enjoyed the attention and "love" given to some degree and may believe they have created the situation or been responsible for the problem. Children and others who are vulnerable are told they will be doing a misdeed if they do not agree to the pressures of the offender, and they are put into the difficult position of having to agree or go against that which they have been taught is authority and must be obeyed. In most cases the offender lets the victim know that there is something wrong about the act itself by the mere fact that the child or individual is sworn to secrecy. In essence, the victim can feel caught in a double bind. This process is also commonly recognized in the workplace and is called "sexual harassment." There is now legislation to protect the victim from molestation and exploitation, including verbal harassment. Those who are not in the workplace deserve the same protection.

Feelings of guilt are further created by offenders in incest situations when they tell the child/victim that to reveal the sexual abuse would be to destroy the family. This sense of culpability can be reinforced by the management of abuse cases when the child, not the parent, is removed from the home. This guilt becomes part of the person as much as does shame and in incorporated into the individual's development. When these incidences remain unidentified and are not appropri- 
ately dealt with the psychological impact of the sexual trauma is carried exclusively and alone.

\section{Recognition and Prevention}

There is a direct correlation between the results of training professionals to understand and identify sexual abuse and the number of cases reported. However low statistics of reported cases do not necessarily mean that the situations do not exist. It is generally recognized in our society that the topic of sexual abuse, exploitation and molestation is a difficult one to discuss, and many people are not comfortable and/or will not believe it occurs. In spite of all this reluctance, it does. David Finklehor reports in his book Sexually Victimized Children ${ }^{8}$ that one in every five female children and one in every ten male children will be sexually abused before the age of eighteen. There is indication that over $80 \%$ of the sexual abuse of children is by someone the child knows, not a stranger. However, in a study conducted by the Seattle Rape Relief and Sexual Assault Center ${ }^{9}$ over a seven year period, it was revealed that $99 \%$ of developmentally disabled reported victims were sexually abused by relatives and caretakers (residential staff, bus drivers, recreation workers, volunteers, work supervisors and others serving in care-provider capacities). Only one percent were strangers to the victim. These are dramatic statistics and serve to alert all of us working in the area of rehabilitation health care. As a first step toward prevention, we must begin to realize that sexual abuse is common. The most recent statistics and general unpublished reports reflect that the number and incidence is higher than has been previously documented in the literature. Some therapists and mental health workers with sex offenders report or discuss among themselves the possibility that perhaps as many as one in three girls experiences molestation by the time she is fourteen and that perhaps as much as $50 \%$ of the victimization occurs within the family.

Prevention of sexual abuse starts with recognition and acknowledgement that it is happening. Many victims of sexual abuse suffer long-term and permanent effects not only of shame, guilt, fear and lowered self-esteem, but also health disorders, learning problems, delinquent behavior and chem- 
ical abuse. ${ }^{2}$ Efforts aimed at prevention must necessarily involve an intention to stop assaults before they occur. It is essential to identify and change societal beliefs and norms which permit sexual abuse and exploitation to continue. The power structure in our society sets up males as more powerful than females, able-bodied persons as more powerful than the physically disabled, white persons as more powerful than those of other color, the wealthy as more powerful than the poor, and adults as more powerful than children. The child or disabled individual is particularly a candidate to be victimized since there is an imbalance of age, size, power, self-control or knowledge.

Children have the right to grow in a safe environment. Because they are vulnerable, they look to adults for protection. As previously mentioned, victims of sexual abuse are often tricked, not forced, by the offender who is likely to be someone the child knows and trusts. It is easy to understand that the child may not believe or even perceive that this person could/would possibly ever hurt him/her. The same rationale can be applied to adult individuals with intellectual or physical disabilities, those who are institutionalized, the elderly.

Prevention efforts must include programs for individuals which inform them of their right to trust their feelings, to say "no," to tell someone, to live in a safe environment, to not permit any touch or behavior which frightens, confuses or hurts them.

The media in the recent five years has made great strides toward publicizing this problem which is reaching national health hazard proportions. General information, highly publicized public service events and announcements, docu-dramas, talk shows, special news reports help increase public awareness and reporting. In an effort to teach individuals some prevention techniques, the books, media, theater companies, and instructions include basic guidelines:

- say "no" if touch or situation is uncomfortable

- tell someone if help is needed

- do not keep secrets if it feels uncomfortable

- ask questions if confused or frightened by touch behavior

- right to privacy and to not permit anyone else to touch 
their body in any way without permission

- right to be taught appropriate touch behavior

- right to learn alternative ways of expressing affection without intimate or inappropriate touch

\section{Indications of Sexual Abuse}

Suspicion of sexual abuse is indicated if:

- clothing appears stained or bloody

- there are reports of injury or neglect by the parents

- the child (victim) has a diagnosis of venereal disease of eyes, mouth, anus, genetalia

- the child (victim) reports pain or itching, bruises or bleeding in the genital area

- overadaptive behaviors that meet the parents' needs rather than the child's (victim's)

- there is extreme fearfulness, withdrawal or fantasy

- the child (victim) exhibits behavioral extremes (passive, overly compliant to rageful and extremely aggressive), stealing or hoarding, habit disorders or neurotic traits, hyperactivity, running away, lagging in development

- there is severe emotional conflict at home

- the child (victim) shows fear of intervention

- there is past history of abuse by the parent or parents

- there is an unwanted pregnancy

- there is inappropriate dress

- there is seductive behavior

- sleep disturbances are being manifested

- there are mood swings, feelings of humiliation, anger, nightmares, eating pattern disturbances, fear of sex, development of phobias about the attack

Specialists who work in the field of sexual abuse consistently state that when an individual does take the risk to identify the abuse and report information related to sexual exploitation or activities, it is crucial that he or she is believed. It may be the only time they risk revealing the taboo and may be the only cry for help which will be given.

There is relatively little written on the topic of sexual abuse and individuals with physical disabilities. However, with the statistics which are available, combined with the knowledge 
of the personal and societal pressures generally experienced by an individual with a disability, it is not difficult to understand that physically disabled persons are potentially at higher risk than the general population. The mere fact that they are in many ways more dependent on the care-providers to assist them in activities of daily living creates multiple opportunities for them to be vulnerable in ways that the ablebodied are not. Not only do they lack privacy, but also they may lack the ability to be spontaneous in protecting themselves. Many individuals are without speech or language abilities and limited in or without mobility. Some may be so totally dependent on others for health care needs for daily living survival that to consider resisting anything from a care-provider or family member may seem too frightening for their own existence. They may also not know in whom to confide for assistance were they to try to identify abusive behavior. They may already have experienced a disenfranchisement from society and would not be willing to risk a further separation. It is understandable that handicappers may predict that their stories might not be believed because their credibility would be pitted against that of an able-bodied person. It is commonly recognized that many sex offenders are viewed as pillars of the community-respected and trusted. Offenders themselves often state that they are aware of the vulnerability of their victims and deliberately plan this abuse since the likelihood of its being reported is minimal.

The emotional reactions and adjustments of someone who has been denied his or her personal integrity by being assaulted are the same as those of someone who has been denied personal integrity by being institutionalized. Because of the denial of freedom, personal decision-making, privacy, economics, independence, and decreased feelings of personal strength, many persons who have been institutionalized share outward characteristics which indicate a history of abuse. ${ }^{10}$ This makes recognition somewhat difficult at times.

An obvious preventive measure is to encourage and assist parents and families in being comfortable with discussing sex and sexuality and in having the skills and information necessary to provide sex education and prevention techniques. Often parents have difficulty doing so. They may not have received any particular education in sexual health and may find 
themselves limited and perhaps confused in their own knowledge and skills. This leads many families to avoid the issue and to cloak it in further silence. Individuals who live in institutions may experience the same kind of silence from the institutional staff for the same reasons.

Sexual abuse is not restricted to any social or economic class and, contrary to some popular belief, parents with higher levels of education or income are not providing better sex education and abuse-prevention techniques than parents who have less education and a lower income. A family containing a physically disabled member, particularly a child, is often seen closing around that individual in a self-containing way in an effort to protect itself from the community and society. Not only might a family be naturally more protective of a child with a disability but also it might isolate itself in a cautious way from society and its insensitivities. Although it is subtle, it creates yet another barrier for the sexually abused, disabled child who might otherwise reach out. Frequently the only community the disabled child knows is that of the family and the care-providers upon whom she or he is dependent.

Although evidence indicates that most children don't reveal their victimization and, even when they do, that many families try to shroud the incident in silence lest they call attention to themselves and sexually inappropriate behavior or make a false accusation, increased numbers of treatment programs are needed to respond to victims. All children, particularly the disabled, must be taught personal safety lessons, preventing sexual abuse, and protecting the right and dignity of their well-being. Books have been written for children helping them to identify "good" and "bad" touch. Audio-visual materials are being created regularly, materials are being written for families to use together and efforts are being taken to train professionals to recognize and identify the events surrounding sexual exploitation. However, in an effort to adequately prepare children to recognize sexually exploitive situations, they must understand that a normal looking person, or even someone they know, could molest them. Most importantly, they must be given the message that they can tell anything to the parent or a trusted adult and that they will be believed and loved. If we can teach the children to say "no" and to yell for safety, even if a family member, the local school 
coach or teacher, attendant, scout leader, transporter or the next door neighbor are the abuser, we will participate in enabling safety for the vulnerable individual.

Reporting is also directly proportional to the number of education programs operating in the community; and although children often know the difference between touch which is given in love and exploitive touch, they are generally reluctant to acknowledge this unless asked directly by a trusted individual and in what they perceive to be a safe setting, free from harm.

Linda Sanford, in her brochure for parents entitled "Come Tell Me Right Away," emphasizes that we must tell the children that we believe them, that the offender did something wrong and that it is not the child's fault. We must report to the authorities (professionals are obligated by law to report suspected sexual exploitation within twenty-four hours.) She instructs that we not confront the offender in the child's presence and that we be sure that the child has a physical examination to reassure him/her that his/her body has not been harmed or changed. Most importantly, she stresses that we allow the child to talk about the incident at his or her own pace, that counseling is helpful and that covering up the incident will not make it go away. The same criteria is applicable for other vulerable persons.

\section{Myths}

Some of the more common myths about sexual exploitation, particularly as it relates to disability, are that nice girls don't get raped, that society feels compassion toward disabled individuals and therefore would not think to do such a thing, that people who are handicapped are not really sexual or attractive and are therefore not eligible to be sexually assaulted, that rapists/abusers are strangers to their victims; that someone who can't speak or doesn't have full mental capabilities wouldn't really understand what happened to them anyway and also probably can't be believed. Other myths are that the mentally retarded or physically disabled lie about assault or are promiscuous and "ask for what they get." Many disabled individuals may participate in sexual acting out behavior which is then labeled as offensive or inappropriate by care- 
takers. Usually in these circumstances no effort is made to modify the negative behavior. These same individuals are also candidates to be treated in a trivial manner and kept socially isolated, reinforcing their sexual ignorance and ultimate vulnerability. ${ }^{12}$

\section{Recovery}

The most difficult step in recovery from sexual exploitation is actually identifying the sexual abuse. Most therapists acknowledge that "telling the secret" is threatening and traumatizing in and of itself and creates feelings of isolation and further vulnerability. When an individual's life has been violated by a parent or adult who has forced himself or herself as a lover, it results in a loss not unlike that which is experienced with an acquired or traumatic disability. It can be extremely disruptive and create enormous vulnerability. It is common for victims to say "He robbed me of my childhood ... of my dignity," and "I am broken."

Incest continues to be perceived as the most damaging form of sexual abuse because of the ambivalence created between hating and loving the offender-family member. Frequently the offender may have been the more nurturing of the family members, and the victim experiences further isolation and loss by severing this tie.

A recognized common response to sexual abuse of families and of accused offenders is denial, followed by anger toward the victim. This can result in further shame, increased vulnerability and at times panic, retreat, and even rescinding the accusation. When support groups, networks, counseling and therapy can be provided, the therapeutic process can result in reduced suffering and positive, although difficult recovery. The emotional scarring can be pervasive and can affect a person's feelings of safety and well-being for the rest of his/her life.

At times of crisis intervention, it is important to determine what the victim needs: to assess his/her immediate health needs, to be assured that he or she is not at fault and to validate the feelings of fear, anxiety and revulsion being felt. We must stand by and assist the victim with problem solving skills for further situations and we must let the individual 
know that he or she has a right to be safe. These simple guidelines are essential to the healing process.

\section{Responses}

Reluctance to talk about sexual assault and exploitation, particularly of children and those with disabilities, is common. The reasons tend to be consistent throughout our society. Parents are afraid of unnecessarily frightening the child by giving them information about abuse. They are often reluctant to talk about sex education mainly for feelings of inadequacy and discomfort of their own.

It is generally regarded as inadequate to discuss sexual abuse in isolation from sex education. Without the context and perspective of sexual health, it is difficult and very frightening for an individual to understand abuse.

Common community resistance often appears in the form of denial that the issue is really a problem in "our neighborhood". Communities are reluctant to inform the individuals about sexual abuse and sexual information for fear that they will try out all of the sexual activities, act inappropriately, make up false reports or be terrorized. Although most parents support sex education and preventive education for their children, they are most critical of $w h$ provides it. Interestingly, Finklehor ${ }^{13}$ reports that "only $29 \%$ of the parents give their children information about sexual abuse despite their awareness of the prevalence of child sexual abuse." Generally, communities struggle over who should teach prevention programs and how much they should contain and cost. Some community groups suggest task forces or child protection teams should do the training, others say the schools, others the police, clergy, rape centers, parents, etc. It is generally acknowledged that specific, professional training needs to be provided to those who teach these topics.

Another common concern of communities is limited financial resources. Particularly in times when some conservative elements in the community are against sex education, communities are concerned that talking about anything sexual (healthy or otherwise) is inappropriate and will not be supported financially. There are no easy answers to the dilemma of persuading communities to invest in educational programs, but clearly the intervention technicues are necessary if we 
are to continue to provide all individuals, able-bodied and disabled, with the right to sexual health.

It is also timely and appropriate to routinely provide sex education, including the area of sexual exploitation, to professionals working in the health care and rehabilitation milieu. It is time for us to aggressively address these unacceptable situations and establish clear directions which mandate respect, dignity, and integrity.

\section{REFERENCES}

1. Children's Village U.S.A.: Child Abuse and You, National Headquarters Woodland Hills, California.

2. Anderson, Cordelia: No Easy Answers, Secondary Curriculum on Sexual Abuse, Illusion Theatre, Minneapolis, MN. Available from Network Publications, Santa Cruz, CA, 1983.

3. Aiello, Denise, Capkin, Lee, Catania, Holly: Strategies and Techniques for Serving the Disabled Assault Victim: A Pilot Training Program for Providers and Consumers, Sexuality and Disability, Volume 6, Number 3/4, Fall/Winter 1983.

4. Life Magazine: Special Report on Childhood Sexual Assault, December 1984.

5. Finklehor, D.: Child Sexual Abuse: Theory and Research, New York Free Press, New York, 1984.

6. Ryerson, Ellen: Sexual Abuse and Self-Protection Education for Developmentally Disabled Youth: A Priority Need, SIECUS, Where The Action Is, Developmental Disabilities Project, Seattle Rape Relief, 1825 South Jackson, Suite 102, Seattle, WA 98144.

7. Musick, Judith: Patterns of Institutional Sexual Assault, Response to Violence in the Family and Sexual Assault, Volume 7, Number 3, May/June 1984.

8. Finklehor, D.: Sexually Victimized Children, New York Free Press, New York, 1979 .

9. Seattle Rape Relief: The Developmental Disabilities Project, 1825 South Jackson, Suite 102, Seattle, WA 98144.

10. Assault Prevention Training Project: Women Against Rape, P.O. Box 82024, Columbus, Ohio 43202.

11. Sanford, Linda Tschirhart: Come Tell Me Right Away, Ed-U-Press Inc., P.O. Box 583, Fayetteville, NY 13066, 1982.

12. O'Day, Bonnie - Minnesota Program for Victims of Sexual Assault: Preventing Sexual Abuse of Persons with Disabilities: A Curriculum for Hearing Impaired, Physically Disabled, Blind and Mentally Retarded Students, Network Publications, Santa Cruz, CA, 1983.

13. Finklehor, D.: Public Knowledge and Attitudes about Child Sexual Abuse: A Boston Survey, Paper presented to the National Conference on Child Sexual Abuse, Washington, D.C., 1982. 


\section{FURTHER RECOMMENDED READING:}

- Aiello, Denise and Capkin, Lee: Services for Disabled Victims: Elements and Standards, Response To Violence in the Family and Sexual Assault, Fall 1984.

- Stuart, Charles and Stuart, Virginia: Sexual Assault: Disabled Perspective, Sexuality and Disability, Volume 4, Number 4, Fall 1981.

- Sexual Assault: The Facts, Response to Violence in the Family and Sexual Assault, Volume 7, Number 2.

- Crime Prevention Tips For Persons With Impairments, Washtenaw County Crime Prevention Task Force for Persons with Impairments, Ann Arbor Police Department, Crime Prevention Unit, Ann Arbor, Michigan, 1984. 